\title{
PERMEATION RATES FOR RTF METAL HYDRIDE VESSELS (U)
}

by J. E. Klein

Westinghouse Savannah River Company

Savannah River Site

Aiken, South Carolina 29808

This paper was prepared in connection with work done under Contract No. DE-AC09-89SR18035 with the U. S. Department of Energy. By acceptance of this paper, the publisher and/or recipient acknowledges the U.S. Government's right to retain a nonexclusive, royalty-free license in and to any copyright covering this paper, along with the right to reproduce and to authorize others to reproduce all or part of the copyrighted paper. 


\section{DISCLAIMER}

This report was prepared as an account of work sponsored by an agency of the United States Government. Neither the United States Government nor any agency thereof, nor any of their employees, makes any warranty, express or implied, or assumes any legal liability or responsibility for the accuracy, completencss, or usefulness of any information, apparatus, product, or process disclosed, or represents that its use would not infringe privately owned rights. Reference herein to any specific commercial product, process, or service by trade name, trademark, manufacturer, or otherwise does not necessarily constitute or imply its endorsement, recommendation, or favoring by the United States Government or any agency thereof. The views and opinions of authors expressed herein do not necessarily state or reflect those of the United States Government or any agency thereof.

This report has been reproduced directly from the best available copy.

Available to DOE and DOE contractors from the Office of Scientific and Technical Information, P. O. Box 62, Oak Ridge, TN 37831; prices available from (615) $576-8401$.

Available to the public from the National Technical Information Service, U. S. Department of Commerce, 5285 Port Royal Rd., Springfield, VA 22161. 


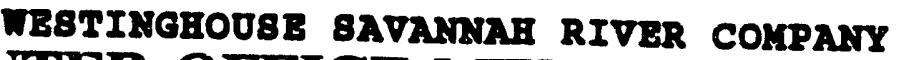 \\ INTER-OFFICE MEMORANDUM}

WSRC-TR-92-258

May 21, 1992

CC: T. Motyka, 773-A

R.H. Hsu, 232-H

A.F. Riechman, 773-A

A. Nobile, 773-A

L.K. Heung, 773-A

M.W. Lee, 773-43A

J.H. Owen, 773-A

F.B. Ramirez, 773-A

J.E. Klein, 773-A

M.L. Moore, 773-A

M.J. Morgan, 773-A

E.A. Clark, 77.3-A

D.J. Green, 235-H

C. Gurosik, 233-5H

R.D. Buley, 233-5H

R.F. Hashinger, 233-19H

M.J. Montini, 233-25H

M.J. Kantz, 233-25H

SRL Records (5), 773-A

To: R. Pedde, 233-H

From: $\quad$ J.R. Knight, 773-A

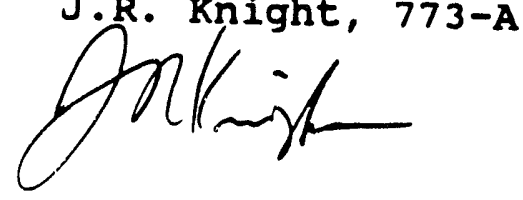

PERYEATION RATES FOR RTP METAL HYDRIDE VES8ELS (O)

Contamination rates have been estimated for the RTF nitrogen heating and cooling system (NH\&CS) due to tritium permeation through the walls of metal hydride vessels. Tritium contamination of the NH\&CS will be seen shortly after start-up of the RTF with the majority of it coming from the TCAP units. Tritium contamination may elevate tritium concentrations in the
NH\&CS above $6 \times 10^{-3} \mu \mathrm{Ci} / \mathrm{CC}$.

To reduce tritium activity in the NH\&CS, a stripper or "getter" bed may need to be installed in the NH\&CS. Increasing the purge rate of nitrogen from the NH\&CS is shown to be an impractical method for;reducing tritium activity due to the high purge rates required. Stripping of the NH\&CS nitrogen in the glove box stripper system will give a temporary lowering of tritium activity in the NH\&CS, but tritium activity will return to its previous level in approximately two weeks. 
To: J.R. Knight, $773-A$

From: J.E. Klein, 773-A $/ \mathcal{C}$

PERKEATION RATES FOR RTF METAL HYDRIDE VE88EL8 (ס)

SOYOERRY

Contamination rates have been estimated for the RTF nitrogen heating and cooling system (NH\&CS) due to tritium permeation through the walls of metal hydride vessels. Tritium contamination of the NH\&CS will be seen shortly after start-up of the RTF with the majority of it coming from the TCAP units. Contamination rates of the NH\&CS are estimated to exceed 400 Ci/year after three years of operation and will elevate tritium concentrations in the NH\&CS above $6 \times 10^{-3} \mu \mathrm{Ci} / \mathrm{CC}$.

To reduce tritium activity in the NH\&CS, a stripper or "getter" bed may need to be installed in the NH\&CS. Increasing the purge rate of nitrogen from the NH\&CS is shown to be an impractical method for reducing tritium activity due to the high purge rates required. Stripping of the NH\&CS nitrogen in the glove box stripper system will give a temporary lowering of tritium activity in the NH\&CS, but tritium activity will return to its previous level in approximately two weeks.

\section{INTRODUCTIOA}

This report estimates the rate of tritium permeation from RTF metal hydride vessels into the RTF NH\&CS. The impact these permeation rates have on the tritium activity in the NH\&CS are discussed. These data were requested for determining the set point of the NH\&CS Kanne chamber.

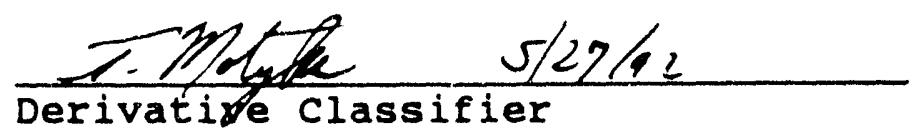


RTF process rooms will be evacuated when tritium activity exceeds $1 \times 10^{-5} \mu \mathrm{Ci} / \mathrm{CC}$. It is desirable to maintain the tritium activity in the event of a nitrogen leak into mize the risk to personnel and purge control of the NH\&CS nitrogen weres room. stripping for controlling tritium activity.

The calculations in this report include tritium permeation from the following metal hydride vessels: flow-thru beds, diffuser storage beds, recovery beds, Thermal Cycling Absorption Process (TCAP) feed beds, TCAP product beds, and TCAP. These and secondary hydride compressors contributions from the primary from the scope of work for the RTF.

The transport of isotopes from the hydride vessels into the NH\&CS is assumed to by permeation (diffusion) only. The model used to constant permeation rates assumed isothermal conditions and Pin-hole leaks in welds of at the calculation temperature. increase the rate of tritium transide vessel may significantly is estimated by permeation alone.

\section{DI8C088ION}

\section{Permeation Calculatione}

Permeability of hydrogen isotopes through metal containers is a function of the concentration of the isotopes in the container program developed the of the container. A finite difference analysis of hydrogen syste Savannah River sitel for diffusion rates of tritium fon systems was modified to examine permeation calculated hydrogen isotope and helium concent. Whis program distributions distributions through a structure wall as a function of the applied boundary conditions, the type of material used, the geometry of the vessel, the composition of the hydrogen isotopes, For the permeation calculations, the following conditions were
used:

$304 \mathrm{~L}$ material of construction.

Cylindrical geometry. 
The total pressure of hydrogen isotopes was constant inside the vessels, but the mole fractions of tritium/deuterium may was used since the mix tanks a total pressure of $2.5 \mathrm{~atm}$ value. For TCAP, the pressure variesally limited to this pressure of $3.0 \mathrm{~atm}$ of 1008 trities and an average permeation data will be applied tum was used. These TCAP area. The partial pressures of hydrogen isotopes outside the
vessel wall were taken to be zero.

3 inch scheduie 10 and schedule 40 pipe were used for the hydride beds dimensions rithile 1-1/4" by $0.065^{\prime \prime}$ wall tubing
was used for the TCAP dimensions.

A temperature of $165^{\circ} \mathrm{C}$ was used for the permeation calculations. This is the maximum hot nitrogen gas temperature expected in the annulus of the metal hydride
vessels.

Tritium permeation rates for different pipe schedules and tritium/deuterium mixtures are shown in Figure 1. These results temperature 24 hours for heating at less than day. To calculate the permeation rate scale of Figure 1 by $(24 / x)$ hours per day, multiply the time day the bed is heated.

For an estimate of the permeation rates to be expected in the RTF, it was assumed that the hydride beds would be heated for a per day. This assumption and TCAP would be heated for 12 hours operation of the RTF process and remainder of this report.

The re-scaled permeation rates from Figure 1 are shown in Figure 2 for up to 20 years of operation. These data shown that permeation rates for schedule 40 pipe are significantly lower that tritium permeation from schedule 10 pipe. Figure 2 also shows start-up of the RTF.

\section{Permeation surface Areas}

The permeation surface areas for the beds were based on the outside diameter of 3 inch pipe while TCAP used the outside diameter of 1-1/4" tubing. For the beds, estimates included the surface area of the pipe caps assuming fiat pipe caps. The

$$
-4-
$$




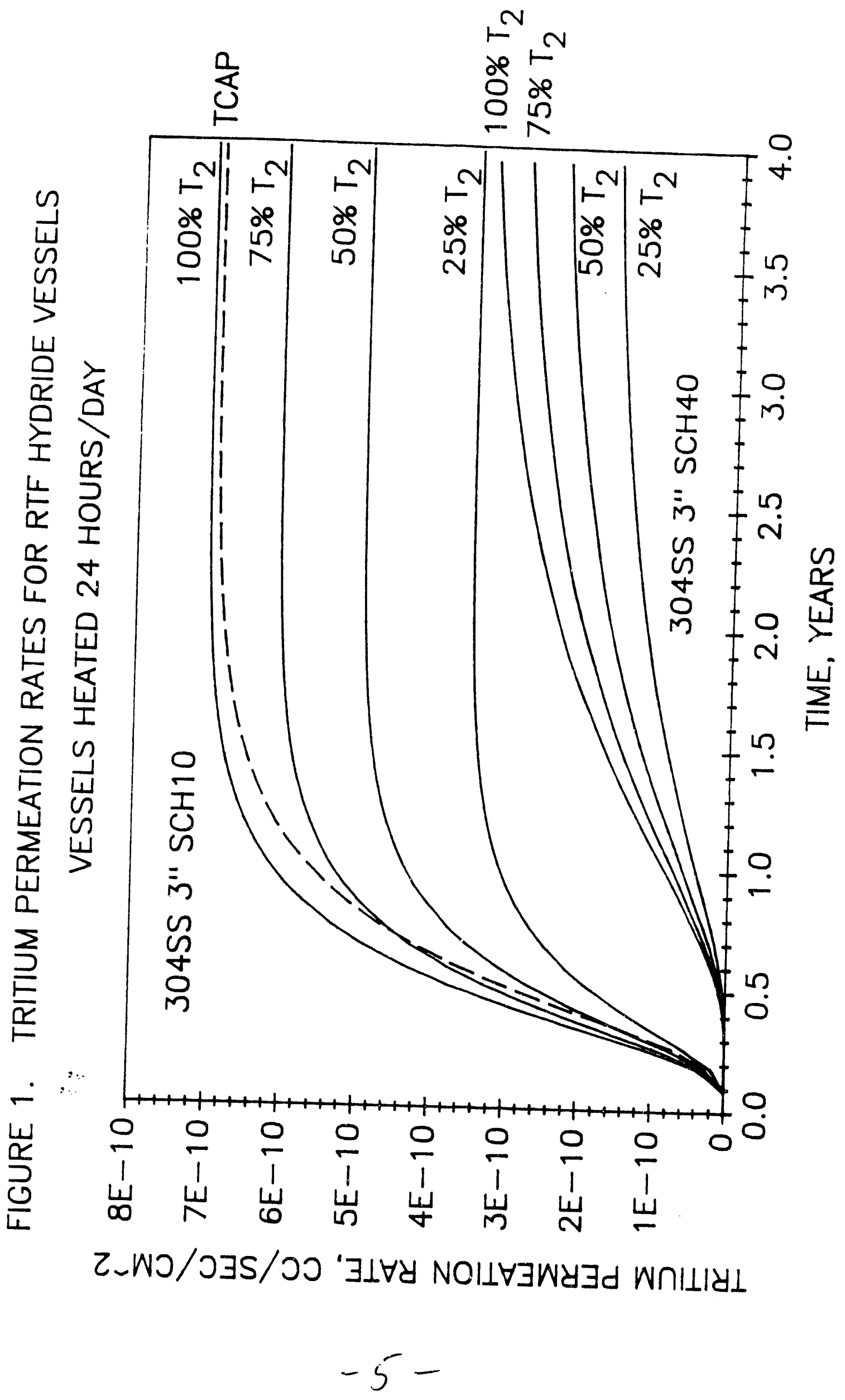




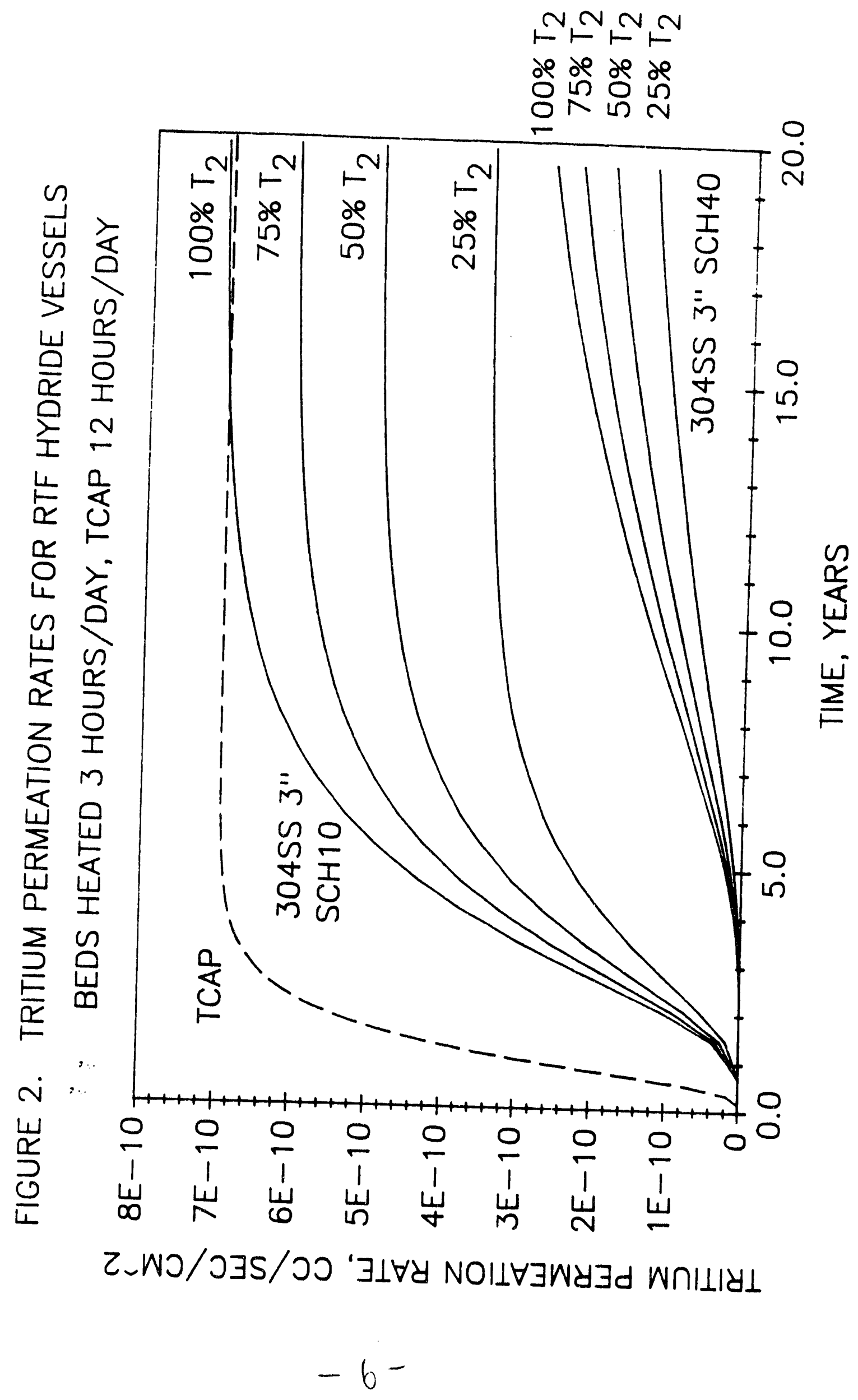


equation used for the beds was

$$
\text { Area } \approx \pi D L+(2) \times \frac{\pi D^{2}}{4}
$$

where $D$ is the outside diameter of the pipe and $L$ is the approximate length of the vessel.

\section{Storage Bed Areas}

Storage beds used in the RTF include the diffuser storage beds, recovery beds, TCAP feed beds, and TCAP product beds (TCAP raffinate beds will not see significant amounts of tritium).

3 inch Sch10 pipe, $I \approx 36$ inches long

Area $\approx 2678 \mathrm{~cm}^{2} /$ bed with a total of 16 beds

\section{Flow-whru Bed Areas}

3 inch Sch10 pipe, $I \approx 60$ inches long

Area $\approx 4380 \mathrm{~cm}^{2} /$ bed with a total of 6 beds

\section{TCAP Areas}

The feed to the TCAP is assumed to be 50 tritium so only $1 / 2$ of the TCAP column will be exposed to tritium and the calculated area will be divided by 2 .

$1-1 / 4$ inch by 0.065 inch wall tubing, I $\approx 40$ feet long

Area $\approx 12,161 \mathrm{~cm}^{2} /$ TCAP with a total of 2 TCAP units

\section{Contanination calculations}

The contamination rate is defined as the rate at which tritium is transported into the NH\&CS. This is equal to the permeation rate for a vessel times its permeation surface area. To get the total contamination rate for the NH\&CS, the contamination rate is summed over all the hydride vessels. 
To compensate for the fact that the hydride vessels are not heated at all times, the contamination rate is calculated using

$$
C_{\text {sate }}=P \times \text { Area } \times 3600 \times \frac{X \text { hours }}{\text { day }} \times 365.25 \times 2.57 \frac{\mathrm{Ci}}{\mathrm{Cm}^{3}}
$$

where $C_{\text {mos }}$ is the contamination rate in $C i$ per year per vessel, $P$ is the permeation rate in SCC tritium per $\mathrm{cm}^{2}$ surface area per sec, $X$ is the number of hours per day the vessel is at its maximum temperature, taken to be 3 for the hydride beds and 12 for TCAP, and the other numbers are for unit conversions.

For RTF operations, it will be assumed that the gas composition present in the hydride vessels preceding TCAP are 508 tritium with the balance being deuterium. With 50 tritium feed to TCAP, it is assumed that $1 / 2$ the TCAP column will be exposed to 1008 tritium during the heating cycle. For the TCAP product beds, the gas composition will be assumed to be 100 tritium.

Figure 3 shows the contamination rates for different tritium compositions and different hydride beds. Additional data are included in this $f$ igure to show how different schedule pipe affects the contamination rate for a particular type of bed. Figure 4 shows the contamination rate for TCAP which is larger than for any of the individual beds.

Contributions to the contamination rates from all the flow-thru beds at 50t tritium, the storage beds at 50 tritium, the storage beds at 100 tritium, and the TCAP units are shown in Figure 5 . Figure 5 also shows the total contamination rate with the TCAP units contributing the major portion of the total contamination rate.

Uncertainties in the permeation calculations will arise from the assumption of constant tritium partial pressure, constant temperature and the amount of time these conditions are maintained. After break-through, the permeation rate is approximately proportional to the partial pressure of tritium contained inside the hydride vessel. Reduction of the tritium partial pressure by a factor of two inside a vessel will decrease the contamination rate from the vessel by approximately $1 / 2$.

An Arrhenius type expression is used to estimate the diffusivity of hydrogẹti isotopes through stainless steel. By reducing the temperature used in the permeation calculations from $165^{\circ} \mathrm{C}$ to $150^{\circ} \mathrm{C}$, the contamination rate for the vessels would be reduced by almost a factor of 2 . Reducing the time the vessels are heated to these temperatures will also reduce the calculated contamination rate. 


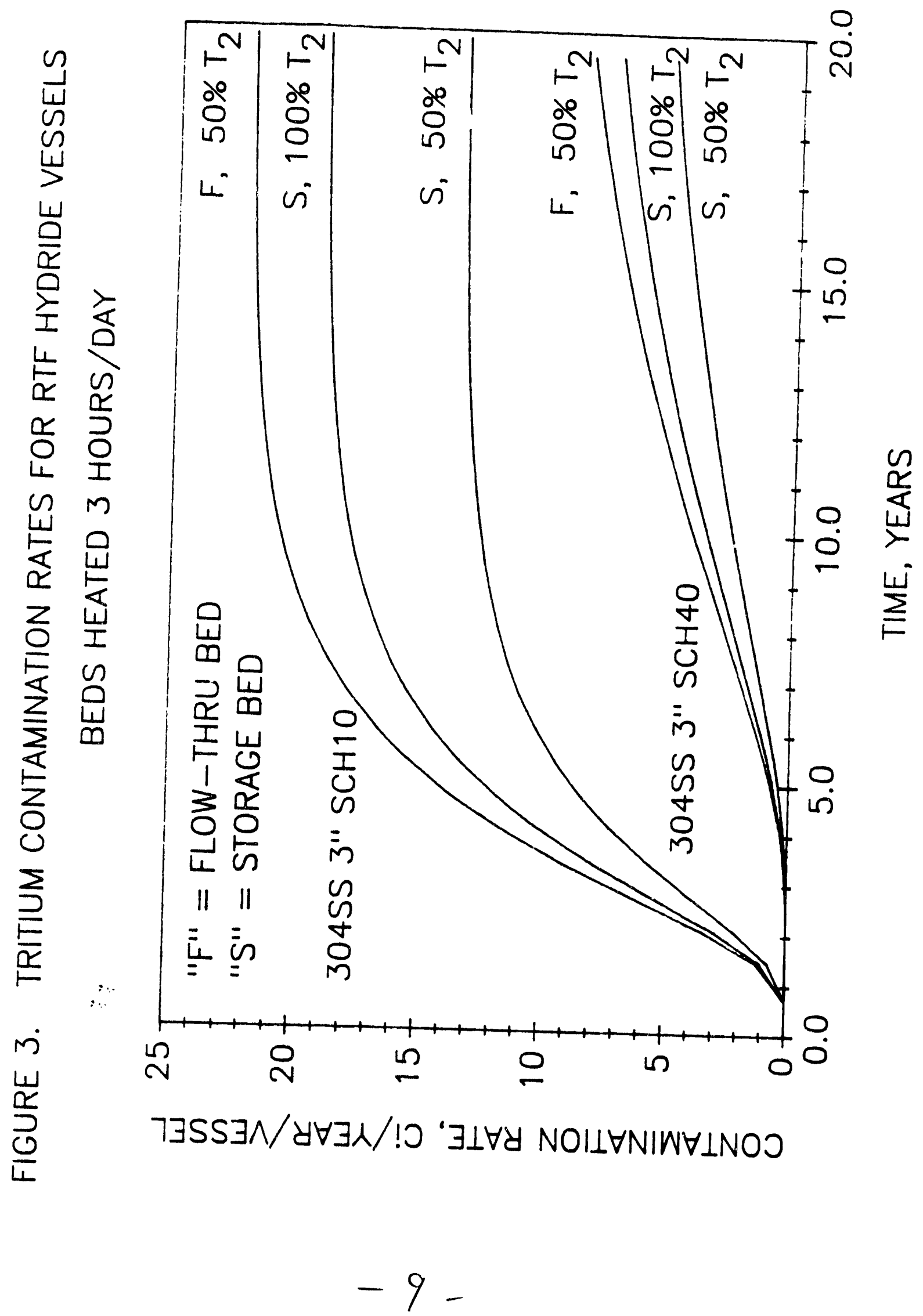




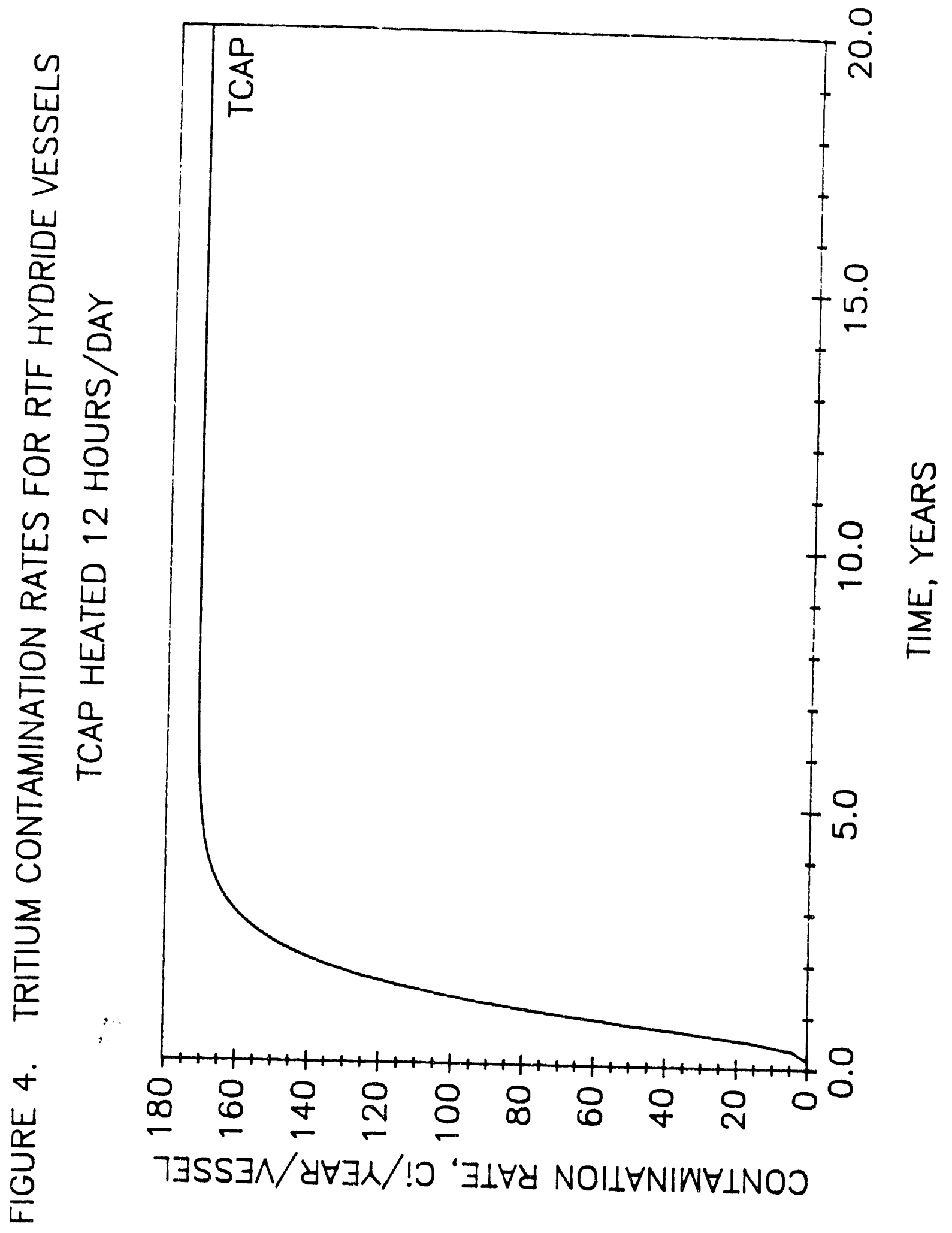




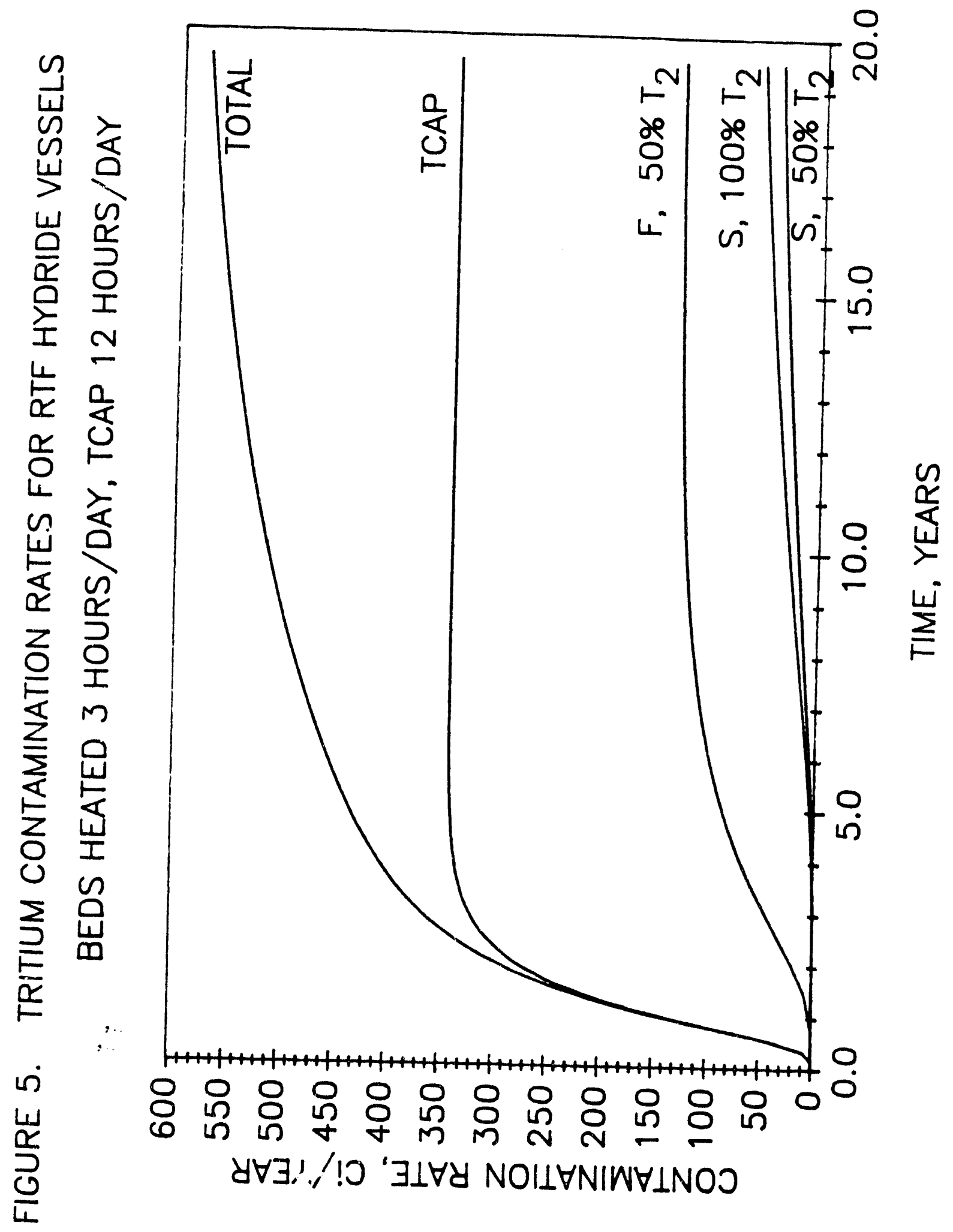




\section{mecs Tritiun Concontration}

The concentration of tritium in the NH\&CS can be estimated by treating the NHECS as a continuous stirred tank reactor (CSTR). Nitrogen inputs to the CSTR includes nitrogen flow from the compressor seal over-pressure system and from nitrogen supplied through the nitrogen make-up system. For steady-state operation, the purge rate from the CSTR must be the same as the inlet flow and if controlled by the flow rate through the purge stripper. The tritium input term for the CSTR is assumed to come only from tritium permeation.

For some initial tritium concentration in the nitrogen system, $c(0)$, the transient response for the CSTR model is given by

$$
C(t)=\frac{Q}{F}\left(1-e^{-\frac{t}{T}}\right)+C(0) e^{-\frac{t}{T}}
$$

where $Q$ is the tritium contamination rate into the system, $F$ is the steady-state nitrogen flow (purge) rate through the system, $t$ is time, and $T$ is time constant for the system and is equal to the volume of the NHeCs, taken to be 3600 SCF, divided by $F$.

The steady-state tritium concentration in the NHECs is given by the ratio $Q / F$. For a purge rate of 1 SCFM, the time constant $T$ is equal to 2.5 days and any transient in the above equation will be negligible after two weeks.

The contamination rates from Figure 5 were used to calculate steady-state tritium concentrations in the NHcCs as a function of time and are shown in Figure 6 for different purge rates. After one year of operation, the nitrogen purge rate can be used to control the tritium activity to between $6 \times 10^{-3} \mu \mathrm{Cl} / \mathrm{cc}$ and $6 \times 10^{-2} \mu \mathrm{Ci} / \mathrm{CC}$. These activities are of the same magnitude as the activities expected in the nitrogen glove atmosphere.

To show if increasing the nitrogen purge rate through the NH\&CS can be used to reduce tritium activity, activity in the NHaCs as a function of nitrogen purge rate is shown in Figure 7 . Figure 7 clearly shows that increasing the nitrogen purge rate through the system is not a practical way to reduce tritium activity in the NH\&CS since the purge/make-up rate is limited to approximately 5 SCFM.

To clean-up the tritium in the NHecs in the stripper system, twelve hours will be required. This is the time required to empty the NHECS nitrogen inventory through the stripper system (limited by the purge stripper at 5 SCFM). As stated before, even after re-filing the NHECs with fresh nitrogen, steady-state

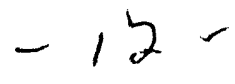




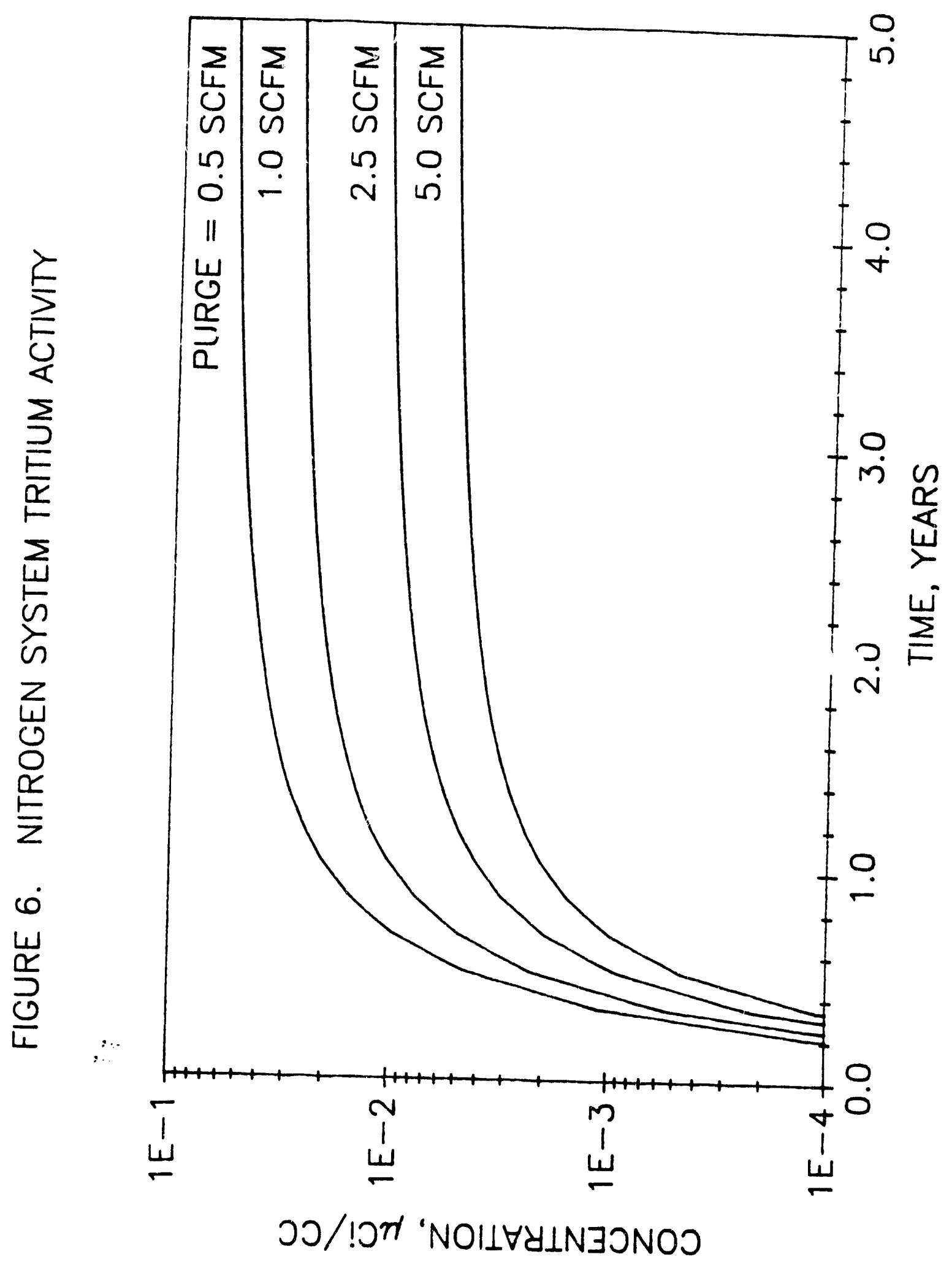

$-13-$ 


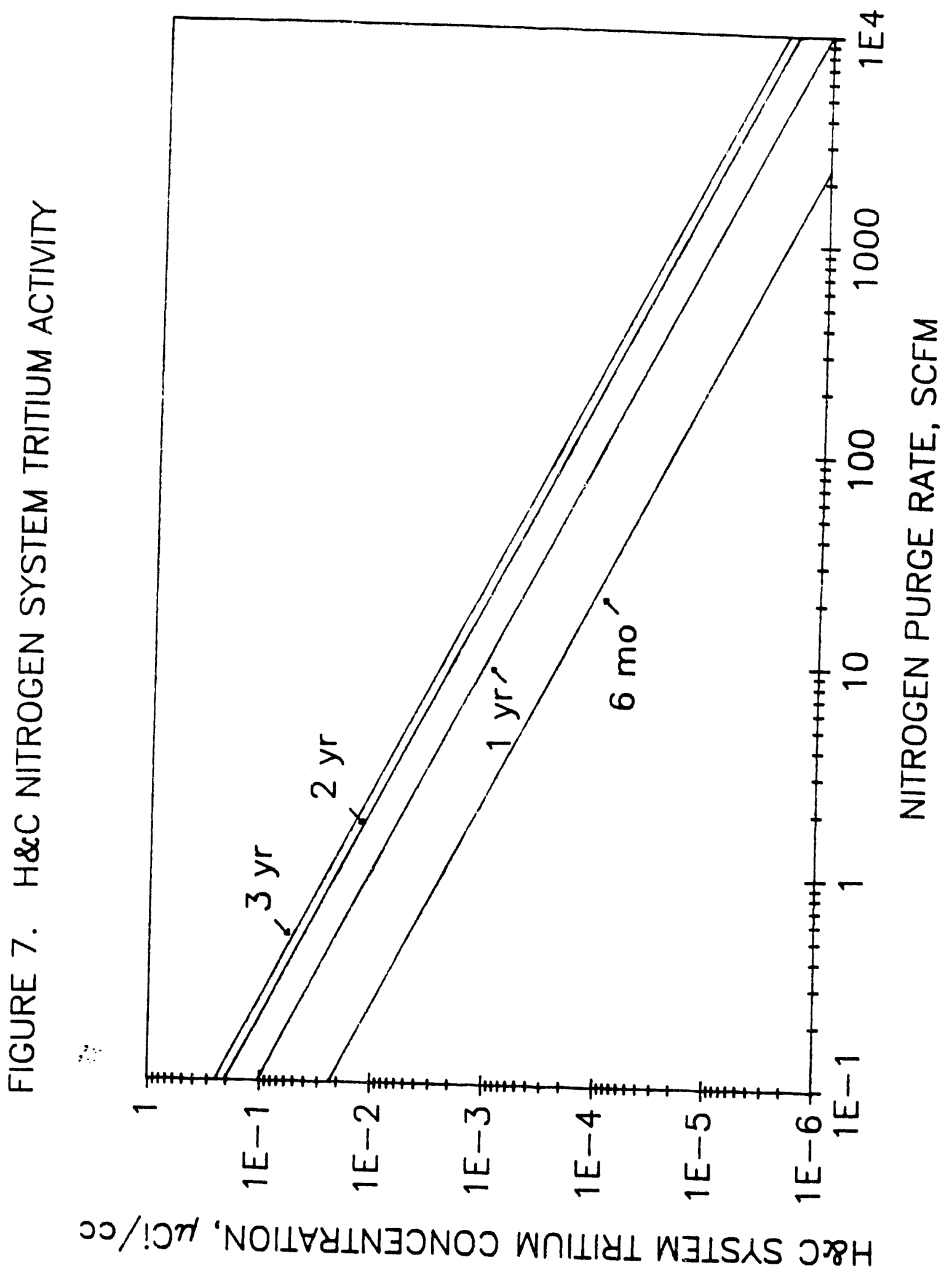

$-142$ 
tritiun concentrations will return to previous levels in approximately two weeks.

\section{COMCLOBIONB}

Tritium permeation through RTF metal hydride vessels will become significant shortly after start-up of the RTF. TCAP is the major contributor to the total tritium contamination rate experienced by the NHeCS. Increasing the nitrogen purge rate through the NH\&CS is not a practical method of reducing tritium activity levels in the NH\&CS. Stripping tritium from the NH\&CS nitrogen using the strippers present in the RTF will take at least $1 / 2$ of a day and will only temporarily reduce tritium activity in the NH\&CS.

To reduce tritium activity levels in the NH\&CS, some type of tritium stripper or "getter" system may need to be installed into the NH\&CS. Several potential tritium getter materials have been identified and are to be tested in the SRTC. Additional steps should also be taken to reduce permeation rates of tritium through the walls of TCAP via alternate TCAP design.

\section{REFEREYCES}

1. Kain, K. E. Finite-Difference Program for Hydrogen Diffusion. USDOE Report DP-1738, Savannah River site, Aiken, SC 29808 (1987). 

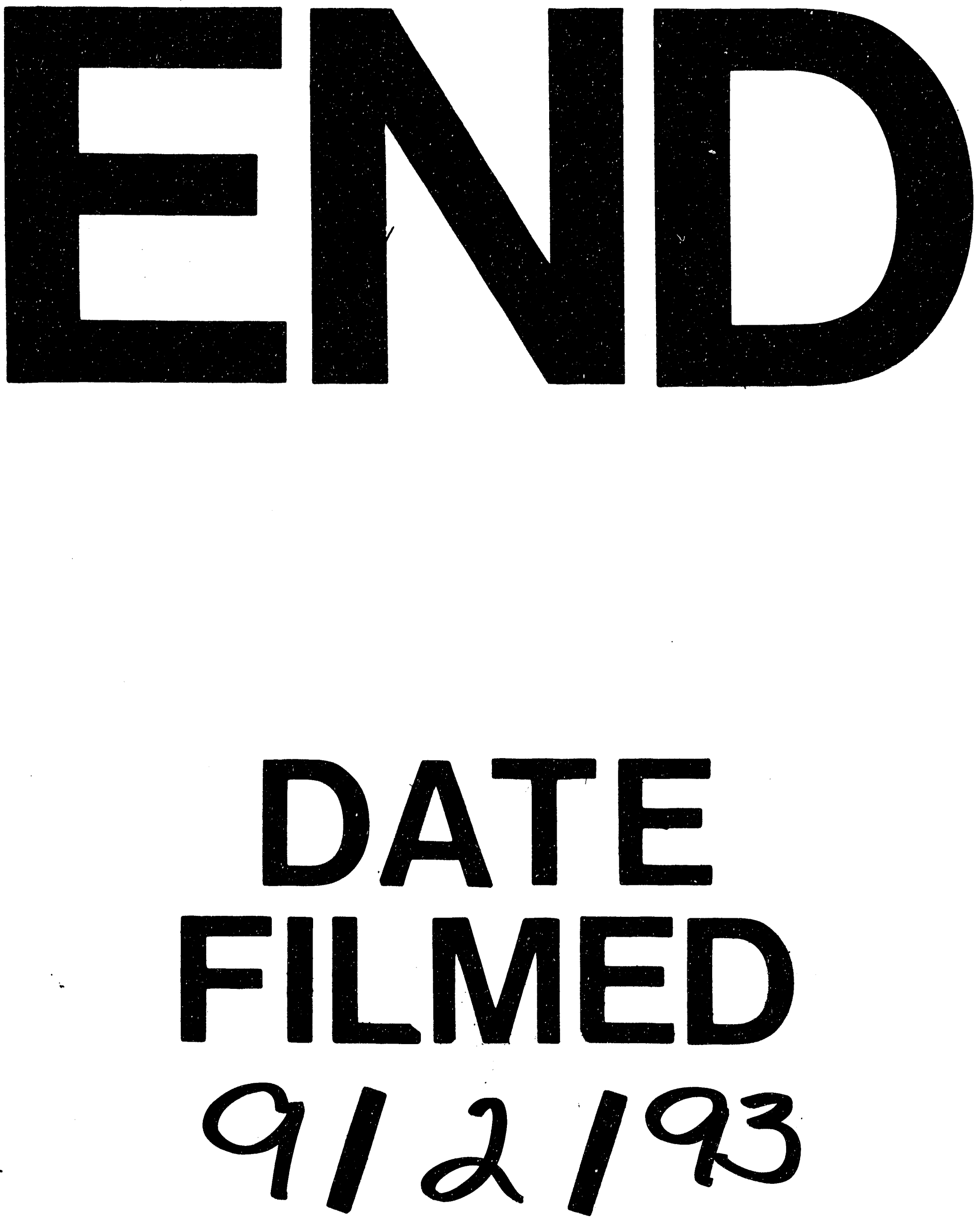
